\title{
Selective and comprehensive analysis of organohalogen compounds by GC $\times$ GC-HRTofMS and MS/MS
}

\author{
Shunji Hashimoto ${ }^{1}$ Yasuyuki Zushi ${ }^{1,2}$ - Yoshikatsu Takazawa ${ }^{1} \cdot \operatorname{Teruyo~Ieda~}^{1}$. \\ Akihiro Fushimi ${ }^{1} \cdot$ Kiyoshi Tanabe $^{1} \cdot$ Yasuyuki Shibata $^{1}$
}

Received: 12 March 2015 / Accepted: 9 July 2015 / Published online: 22 July 2015

(C) The Author(s) 2015. This article is published with open access at Springerlink.com

\begin{abstract}
Thousands of organohalogen compounds, including hazardous chemicals such as polychlorinated biphenyls (PCBs) and other persistent organic pollutants (POPs), were selectively and simultaneously detected and identified with simple, or no, purification from environmental sample extracts by using several advanced methods. The methods used were software extraction from two-dimensional gas chromatography-high-resolution time-of-flight mass spectrometry (GC $\times$ GC-HRTofMS) data, measurement by negative chemical ionization with HRTofMS, and neutral loss scanning (NLS) with GC $\times$ GC-MS/MS. Global and selective detection of organochlorines and bromines in environmental samples such as sediments and fly ash was achieved by NLS using GC $\times$ GC-MS/ MS (QQQ), with the expected losses of ${ }^{35} \mathrm{Cl}$ and ${ }^{79} \mathrm{Br}$. We confirmed that negative chemical ionization was effective for sensitive and selective ionization of organohalogens, even using GC $\times$ GC-HRTofMS. The 2D total ion chromatograms obtained by using negative chemical ionization and selective extraction of organohalogens using original software from data measured by electron impact ionization were very similar; the software thus functioned well to extract organohalogens. Combining measurements made by using
\end{abstract}

Responsible editor: Roland Kallenborn

Electronic supplementary material The online version of this article (doi:10.1007/s11356-015-5059-5) contains supplementary material, which is available to authorized users.

Shunji Hashimoto

shunji@nies.go.jp

1 National Institute for Environmental Studies, Onogawa 16-2, Tsukuba 305-8506, Japan

2 Advanced Industrial Science and Technology, Onogawa 16-1, Tsukuba 305-8569, Japan these different methods will help to detect organohalogens selectively and globally. However, to compare the data obtained by individual measurements, the retention times of the peaks on the $2 \mathrm{D}$ chromatograms need to match.

Keywords Mass defect $\cdot$ Multidimensional data analysis · Neutral loss $\cdot$ Non-target analysis $\cdot$ Software extraction and cleanup

\section{Introduction}

We are surrounded by a variety of chemicals, and indeed, our lives are supported by huge numbers of man-made chemicals such as industrial chemicals, pharmaceuticals, and agrochemicals. However, some of these chemicals have caused, or are currently causing, environmental pollution or are having adverse effects on living organisms. Most persistent organic pollutants (POPs) including dichlorodiphenyltrichloroethane (DDT), hexachlorocyclohexane ( $\mathrm{HCH})$, and polychlorinated biphenyls (PCBs) were initially produced as useful and beneficial chemicals. Those pollutants suggest that some halogenated compounds have the potential for adverse effects on human and environmental health. Unfortunately, the types and concentrations of halogenated compounds in the environment are not fully known, because as yet, there is no measure that can detect all halogenated compounds and identify each of them.

Global detection, which can be used as a non-target analysis to search for large numbers of substances simultaneously, is one approach to addressing the increasingly diverse range of environmental pollutants. Direct measurement of samples without any loss of compounds is ideal for complete, global detection of pollutants. However, the conventional gas chromatograph, which is the mainstream tool for analyzing 
environmental pollutants, cannot separate the huge numbers of compounds contained in a crude sample. In recent years, comprehensive two-dimensional (2D) gas chromatography $(\mathrm{GC} \times \mathrm{GC})$ has been used to characterize hundreds, or perhaps thousands, of petroleum chemicals (Blomberg et al. 1997; von Muhlen et al. 2006; Mao et al. 2009), as well as food components and flavors (Bicchi et al. 1999; Adahchour et al. 2002; Tranchida et al. 2010). GC $\times$ GC technology has also been used to analyze environmental contaminants with many congeners, such as PCBs (Hyotylainen et al. 2002; Korytar et al. 2002; Focant et al. 2003, 2004; Kristenson et al. 2005), polybrominated diphenyl ethers (PBDEs) (Focant et al. 2003; Korytar et al. 2005), and polyaromatic hydrocarbons (PAHs) (Hyotylainen et al. 2002; Kallio and Hyotylainen 2007; Ochiai et al. 2007; Fushimi et al. 2012), as well as polychlorinated dibenzo- $p$-dioxins and dibenzofurans (PCDDs/Fs) (Korytar et al. 2004; Danielsson et al. 2005; Shunji et al. 2008; de Vos et al. 2011). Although most of these studies have focused on the quantification of individual isomers, reports of non-target analysis by using $\mathrm{GC} \times \mathrm{GC}-\mathrm{MS}$ have been increasing in recent years (Hilton 2007; Hilton et al. 2010; Pena-Abaurrea et al. 2014).

In our current studies, we are developing new apparatus consisting of $\mathrm{GC} \times \mathrm{GC}$ directly coupled with quadrupoletype tandem mass spectrometry (MS/MS; QQQ) or highresolution time-of-flight mass spectrometry (HRTofMS), or both. Here, we present the results of one of our studies on the comprehensive and selective detection of halogenated compounds in environmental samples. The method is based on neutral loss scanning (NLS) with $\mathrm{GC} \times \mathrm{GC}-\mathrm{MS} / \mathrm{MS}$ and post-processing of data from $\mathrm{GC} \times \mathrm{GC}-\mathrm{HRTofMS}$ with laboratory-built software. This technique has been reported in our previous papers (Hashimoto et al. 2011, 2013). Additionally, we report the selective detection of organohalogens by using negative chemical ionization $(\mathrm{NCI})$ on $\mathrm{GC} \times \mathrm{GC}-$ HRTofMS and comparison of the results with selective data extracted by using the software. Electron-capture negative ionization, which is a function of NCI reactions, is an effective ionization method for electrophilic molecules such as organohalogens and nitro compounds.

\section{Materials and methods}

Chemicals Carbon-13-labeled and carbon-13-unlabeled polychlorinated dibenzo- $p$-dioxins (PCDDs) were obtained from Wellington Laboratories Inc. (Guelph, ON, Canada); PCDFs, PCBs, and PBDEs from Cambridge Isotope Laboratories Inc. (Tewkesbury, MA, USA); other ${ }^{13} \mathrm{C}$-labeled and ${ }^{13} \mathrm{C}$-unlabeled POPs from Wako Pure Chemical Industries, Ltd. (Osaka, Japan); and 263 unlabeled pesticides from Kanto Chemical Co., Inc. (Tokyo, Japan).
Samples Certified reference materials provided by our institute were used for measurement as environmental samples. Nos. 17 and 20 were fly ash extract and sediment (note that these samples are currently not available because of low stocks). Soil samples were collected from an industrialized area, dried naturally, and screened with a 320-mesh sieve. Sediment and soil samples were Soxhlet-extracted for $16 \mathrm{~h}$ and then cleaned up with only a sulfuric acid-silica gel column. Indoor and outdoor air samples were collected into a Tenax-TA tube (Gerstel GmbH \& Co. KG, Mülheim an der Ruhr, Germany) in our laboratory and on the rooftop of a building at our institute for a week. Samples of approximately $300 \mathrm{ml}$ of urine were collected from each of two healthy adult males and combined. A portion (approximately $50 \mathrm{ml}$ ) of the combined sample was extracted with hexane.

Measurement by $\mathbf{G C} \times \mathbf{G C}-\mathbf{Q Q Q}$ with $\mathrm{NLS}$ Measurement instruments and conditions are summarized in Table 1. Crude extract solutions of sediments, soils, and fly ash, and the contents of the Tenax-TA tubes that had adsorbed the indoor and outdoor air, were quantified with an Agilent 7890GC (Agilent Technologies, Santa Clara, CA, USA) with a Zoex KT-2006 GC $\times$ GC system (Zoex Corporation, Houston, TX, USA) coupled with an Agilent 7000 QQQ with NLS mode (Shunji et al. 2008).

Measurement by $\mathbf{G C} \times \mathbf{G C}-\mathbf{H R o f M S}$ The same samples used for measurement by $\mathrm{GC} \times \mathrm{GC}-\mathrm{MS} / \mathrm{MS}$, and the human urine samples, were newly quantified with an Agilent $6890 \mathrm{GC}$ with a Zoex KT-2004 GC $\times$ GC system coupled with a JEOL JMS-T100GC (JEOL Ltd., Tokyo, Japan), or with an Agilent $7890 \mathrm{GC}$ with a Zoex KT-2006 GC $\times$ GC system coupled with a JEOL JMS-T100GCV 4G (Hashimoto et al. 2011, 2013).

For measurement with the JMS-T100GCV 4G, we also employed NCI for selective ionization of organohalogens, as well as electron ionization (EI).

\section{Processing for extraction of organohalogens from GC $\times$} GC-HRTofMS data We developed software that extracts only the mass spectra of organochlorines or organobromines from the data measured by the GC $\times$ GC-HRTofMS system. The software reads a netCDF file as input data, and extracts from the whole data set only those mass spectra that have chlorine or bromine isotopic patterns. For this process, the software never requires target mass setting (Hashimoto et al. 2013). It can vary the parameters - namely the mass accuracy, including mass resolution, mass range, threshold of signal intensity, and margin of error of the theoretical isotopic ratio of chlorine or bromine - for data extraction. It can also optionally pre-screen data by checking for mass defects, which are usually observed when the compound includes atoms such as 
Table $1 \mathrm{GC} \times \mathrm{GC}-\mathrm{MS} / \mathrm{MS}$ (QQQ) and TD-GC $\times$ GCHRTofMS conditions used to analyze environmental samples

\begin{tabular}{|c|c|}
\hline \multicolumn{2}{|l|}{$\mathrm{TD}^{\mathrm{a}}$} \\
\hline Thermal desorption & Gerstel TDU \\
\hline & $\begin{array}{l}\text { Transfer mode: fix; temp.: } 340{ }^{\circ} \mathrm{C} \text {; desorption mode: splitless; sample mode: } \\
\left.\text { sample remove from } 40{ }^{\circ} \mathrm{C} \text { holding for } 1 \mathrm{~min} \text { (delay } 0.5+\text { initial } 0.5\right) \text { to } \\
180{ }^{\circ} \mathrm{C} \text { at rate } 720{ }^{\circ} \mathrm{C} \min ^{-1} \text { holding for } 0 \mathrm{~min} \text { to } 340{ }^{\circ} \mathrm{C} \text { at rate } 50{ }^{\circ} \mathrm{C} \\
\min ^{-1} \text { holding for } 5 \mathrm{~min}\end{array}$ \\
\hline \multirow[t]{2}{*}{ Cryo-focusing } & Gerstel CIS4 \\
\hline & $\begin{array}{l}\text { Heater mode: standard, cryo-cooling: enables from } 0{ }^{\circ} \mathrm{C} \text { holding for } 0.2 \mathrm{~min} \\
\text { (equilibrium } 0.1+\text { initial 0.1) to } 300{ }^{\circ} \mathrm{C} \text { at rate } 12{ }^{\circ} \mathrm{C} \mathrm{min}{ }^{-1} \text { holding for } 3 \mathrm{~min}\end{array}$ \\
\hline \multicolumn{2}{|l|}{$\mathrm{GC} \times \mathrm{GC}$} \\
\hline Instrument & Agilent $7890 \mathrm{GC}$ or Agilent $6890 \mathrm{GC}$ \\
\hline $\mathrm{GC} \times \mathrm{GC}$ & Zoex KT2004 (in 6890GC) or Zoex KT2006 (in 7890GC) \\
\hline 1 st column & GL Science InertCap 5MS/Sil (45 m length, $0.25 \mathrm{~mm}$ i.d., $0.1-\mu \mathrm{m}$ film thickness) \\
\hline 2nd column & SGE BPX-50 (1 m length, $0.1 \mathrm{~mm}$ i.d., 0.1- $\mu \mathrm{m}$ film thickness) \\
\hline Oven program & $\begin{array}{l}\text { From } 70{ }^{\circ} \mathrm{C} \text { holding for } 1 \mathrm{~min}^{-10} 180{ }^{\circ} \mathrm{C} \text { at rate } 50{ }^{\circ} \mathrm{C} \mathrm{min} \min ^{-1} \text { holding for } 0 \mathrm{~min} \\
\text { to } 230{ }^{\circ} \mathrm{C} \text { at rate } 3{ }^{\circ} \mathrm{C} \mathrm{min}{\text { molding for } 0 \mathrm{~min} \text { to } 300{ }^{\circ} \mathrm{C} \text { at rate } 5{ }^{\circ} \mathrm{C} \mathrm{min}}^{-1} \text { hold } \\
\text { holding for } 16.133 \mathrm{~min} \text { (total } 50 \mathrm{~min} \text { ) }\end{array}$ \\
\hline Injection & Volume: $1 \mu$, temp: $280{ }^{\circ} \mathrm{C}$; method: splitless or solvent vent for TDU \\
\hline Carrier gas & Type: He; mode: constant flow; initial head pressure: $246 \mathrm{kPa}$ at $70{ }^{\circ} \mathrm{C}$ \\
\hline Modulation & Period: $4 \mathrm{~s}$; releasing: $0.25 \mathrm{~s}$ \\
\hline \multicolumn{2}{|l|}{ MS/MS } \\
\hline Instrument & Agilent 7000A QQQ (7000B equivalent) \\
\hline Ion source & Mode: EI+; temp: $250{ }^{\circ} \mathrm{C}$; ionizing voltage: 40 or $70 \mathrm{~V}$; ionizing current: $35 \mu \mathrm{A}$ \\
\hline \multirow[t]{2}{*}{ Analyzer } & Mode: neutral loss scan, monitoring loss*: $19,35,37,79$, and $81 \mathrm{~m} / \mathrm{z}$ \\
\hline & Scan range: $150-530 \mathrm{~m} / z$; cycle: $20 \mathrm{~Hz}$ \\
\hline \multicolumn{2}{|l|}{ HRTofMS } \\
\hline Instrument & JEOL JMS-T100GC or JEOL JMS-T100GCV 4G (NIES edition) \\
\hline \multirow[t]{3}{*}{ Ion source } & i) mode: $\mathrm{EI}+$; temp: $260{ }^{\circ} \mathrm{C}$; ionizing voltage: $70 \mathrm{eV}$; ionizing current: $600 \mu \mathrm{A}$ \\
\hline & $\begin{array}{l}\text { ii) mode: CI- (NCI); reaction gas; } \mathrm{CH} 4 \text { or } \operatorname{Ar}\left(\text { trial); } 0.5 \mathrm{ml} / \mathrm{min} \text {; temp: } 250{ }^{\circ} \mathrm{C} \text {; }\right. \\
\text { ionizing voltage: } 70 \mathrm{eV} \text {; ionizing current: } 600 \mu \mathrm{A}\end{array}$ \\
\hline & iii) mode: $\mathrm{FI}+$; temp: $110^{\circ} \mathrm{C}$; counter electrode voltage: $-10,000 \mathrm{~V}$ \\
\hline Analyzer & $\begin{array}{l}\text { Mass resolution: } 8000-10,000 \text { (best effort); recording range: } 30-600 \mathrm{~m} / \mathrm{z} \text {; cycle: } \\
33 \mathrm{~Hz}\end{array}$ \\
\hline Detector & MCP voltage: $2000-2400 \mathrm{~V}$ \\
\hline
\end{tabular}

${ }^{a}$ Thermal desorption (TD) was used for desorption of air samples halogens, and by using our method (Hashimoto et al. 2011), which can simulate NLS as a post-filter for the data.

In this software, mass deficiency is used for simple data filtration before $\mathrm{Cl}$ or $\mathrm{Br}$ isotopic pattern checking. Specifically, mass spectra with mass deficiencies within a range of 0 to -0.2 (the default setting for organochlorines) are left in the data, whereas the other spectra are removed. For example, the mass deficiencies of biphenyl $\left(\mathrm{C}_{12} \mathrm{H}_{10}\right)$, pentachlorobiphenyl $\left(\mathrm{PeCB}, \mathrm{C}_{12} \mathrm{H}_{5}{ }^{35} \mathrm{Cl}_{5}\right.$ ), and pentabromobiphenyl (PeBP, $\mathrm{C}_{12} \mathrm{H}_{5}{ }^{79} \mathrm{Br}_{5}$ ) are +0.07825 , -0.1166 , and -0.3692 , respectively; the mass deficiencies of $\mathrm{H},{ }^{35} \mathrm{Cl}$, and ${ }^{79} \mathrm{Br}$ are $+0.007825,-0.03118$, and -0.08166 , respectively. Therefore, application of a mass defect filter (MDF) with a range of 0 to -0.2 leaves the mass spectra of only $\mathrm{PeCB}$; biphenyl and $\mathrm{PeBP}$ are removed from the data set. If the MDF is set to a range of 0 to -0.5 , then, only biphenyl is removed from the data set. Incidentally, the mass deficiencies of four atoms of $\mathrm{H}$ and one atom of ${ }^{35} \mathrm{Cl}$, or of 10 atoms of $\mathrm{H}$ and one atom of ${ }^{79} \mathrm{Br}$, nearly balance.

\section{Results and discussion}

Selective detection of organohalogens by using NLS We successfully detected halogenated compounds comprehensively and selectively from environmental samples by using NLS with GC $\times$ GC-MS/MS (QQQ). The results of NLS for ${ }^{35} \mathrm{Cl}$ (NLS-35), which was expected to selectively detect organochlorines by the loss of ${ }^{35} \mathrm{Cl}$ from molecules, and a conventional scan $(\mathrm{m} / \mathrm{z}=150$ to 530$)$ of the sediment sample are shown as 2D total ion chromatograms (2D-TICs) in Fig. 1. Whereas a huge number of peaks and bands of complex compounds were observed in the chromatogram obtained with conventional scanning, many peaks were isolated by NLS- 
Fig. 1 Two-dimensional total ion chromatograms (TICs) of a sediment sample (NIES CRM20), as measured by ${ }^{35} \mathrm{Cl}$ neutral loss scanning (NLS-35, upper), which was expected to selectively detect organochlorines, and a conventional scan (lower) obtained by using $\mathrm{GC} \times \mathrm{GC}-\mathrm{MS}$ / MS. The red translucent shape in the upper chromatogram shows the area where organohalogens were expected to appear



conventional scan

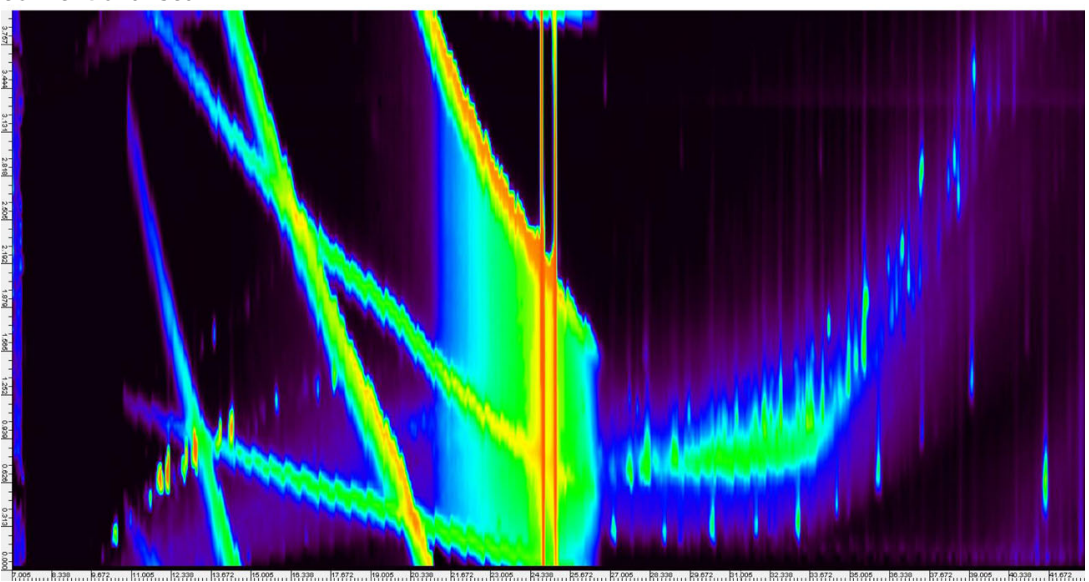

35 of the sediment sample. We then used NLS for ${ }^{79} \mathrm{Br}$ (NLS79), which we expected would selectively detect organobromines, as well as NLS-35, on a crude extract of fly ash. Successful global detection of halogenated compounds was demonstrated by NLS of these halogens using QQQ. However, the sensitivity of NLS is lower than that of conventional scan modes in general-it was $1 / 1000$ to $1 / 100$ as sensitive in the present case, depending on the conditions and the sample. This makes identification difficult, because proper mass spectra cannot be obtained from most peaks by using NLS. Alternatively, it was possible to search for, and identify, compounds by using 2D mass chromatograms and mass profiles obtained from measurements of the same sample with $\mathrm{GC} \times \mathrm{GC}-$ HRTofMS under the same conditions. In direct measurements performed on extracts from fly ash and sediment by using the above apparatus, many dioxin and PCB congeners were identified and many other halogenated compounds were found. A small number of chlorinated PAHs were also identified.

Precise retention-time matching of $\mathrm{GC} \times \mathrm{GC}$ peaks is important to enable the comparison of plural data and thus give better determination. A single gas chromatograph cannot separate the huge number of compounds contained in a crude sample, even when QQQ is used for detection. Therefore, the coupling of $\mathrm{GC} \times \mathrm{GC}$ and QQQ is an effective approach to complete, global detection of organohalogens.

\section{Selective extraction of organohalogens by using software} We also developed a method that selectively extracts a subset of GC $\times$ GC-HRTofMS data to detect and identify trace levels of organohalogens (Hashimoto et al. 2013). By using our original software, namely the "Chlorine and Bromine isotopic profile Extractor" (CBEx), which finds typical peaks including mass clusters associated with the presence of chlorine

Fig. 2 Comparison of the results of mass defect filter $(M D F)$ prescreening of data on three kinds of sample measured by $\mathrm{GC} \times \mathrm{GC}-$ HRTofMS. All total ion chromatograms were processed only by prescreening using an MDF. Typical mass spectra were extracted by using our novel software under the same conditions, namely threshold 0 ; mass range, full; mass accuracy (MA), $0.05 \mathrm{u}$; extracted atom number, 3 to 10 ; and NLS, off, without MDF. ${ }^{1}$ MDF. Mass spectra with mass deficiencies within a 0 to -0.2 range were left in the data; other spectra were removed. ${ }^{2}$ Retention time ( $\mathrm{min}$ ) on the first gas chromatogram. ${ }^{3}$ Retention time (s) on the second gas chromatogram. $a$ Indoor air TIC. $b$ Sediment TIC. $c$ Human urine TIC. This figure was reproduced from the work of Hashimoto et al. (2013) 


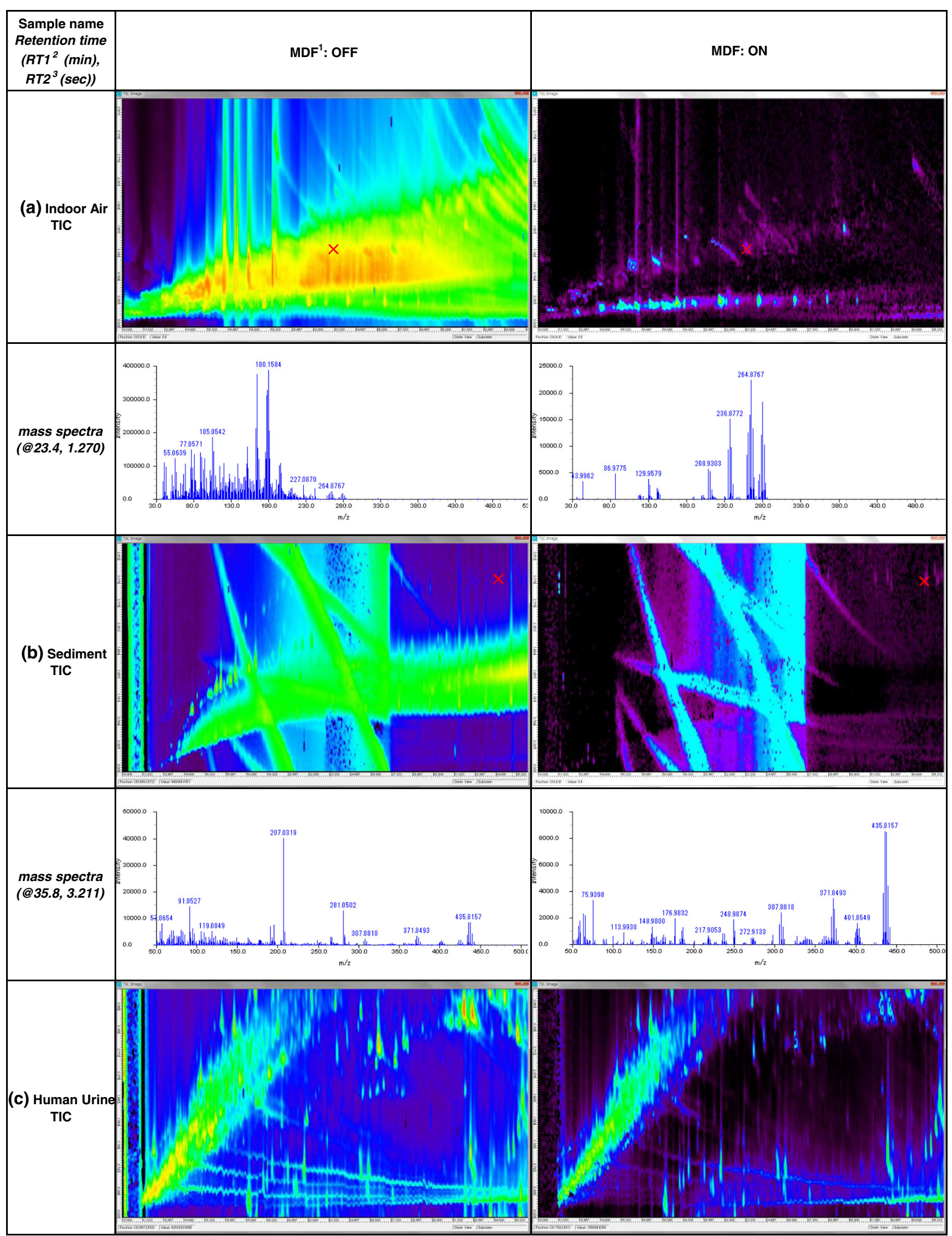


isotopes, we achieved selective extraction of the mass spectra of organochlorines from the huge amounts of data obtained from environmental or biological samples by $\mathrm{GC} \times \mathrm{GC}-$ HRTofMS. Although Hilton (2007) have reported a similar data processing approach, they used unit mass data obtained by $\mathrm{GC} \times \mathrm{GC}-$ TofMS using a Leco Pegasus $4 \mathrm{G}$. Moreover, Pena-Abaurrea et al. (2014) tried to find halogenated compounds in Ontario sediment samples by taking a scripting approach to Pegasus 4G data. To validate the effectiveness of using accurate mass for data extraction, we compared the results obtained by changing the mass width parameter of the software for data extraction. We found that high mass resolution and mass accuracy were valuable for selective extraction of organochlorines or organobromines. Screening by mass defect was effective for removing the mass spectra of hydrocarbons. Three applications of an MDF (one of the data-filtering functions of the software)-for the indoor air, sediment, and human urine data-are shown in Fig. 2. The mass spectra of an abundance of hydrocarbons and their fragments formed by EI were effectively removed by the MDF in the air and sediment samples (Fig. 2a, b). Comparison of the mass spectra before and after processing with the MDF clearly revealed the chlorine isotopic profile. The mass spectra of molecular sulfur in the sediment samples or in metabolites or biological derivatives in the human urine samples could not be removed by the MDF (Fig. 2b, c). Organochlorines were selectively and effectively extracted by the CBEx software after application of the MDF. Direct sample measurement and data extraction by using the software were therefore effective in non-target analysis.

Selective ionization by NCI on GC $\times$ GC-HRTofMS We examined selective ionization by $\mathrm{NCI}$ as another approach to the global and selective detection of organohalogens, because it is known to be effective for ionization of these compounds (Cajka et al. 2005; Carrizo and Grimalt 2006; Hites 2008). The 2D total ion chromatograms of a soil sample measured with EI and NCI are shown in Fig. 3. Many peaks were observed in the EI chromatogram. Fewer peaks appeared in the middle 2D-TIC obtained by NCI; peaks that might have been derived from hydrocarbons and siloxanes were not observed. The bottom 2D-TIC shows the results of selective extraction of organohalogens by CBEx from the data measured with EI. When an MDF range of 0 to -0.2 was used, mass spectra that were likely representative of organochlorines were extracted. The middle and bottom TICs are very similar. Thus, both the software extraction and NCI were effective in detecting organohalogens selectively and comprehensively. The mass spectra of most of the peaks extracted by the software and detected by NCI were confirmed; these spectra have the typical cluster patterns of isotopes of chlorine or bromine. For example, the mass spectra of a peak located in the same position on each of the chromatograms are shown in Fig. 4. Cluster patterns of chlorine isotopes were observed in all the mass spectra. The NCI (middle) results show only a few mass spectra. A NIST 11 library search identified the processed spectrum (bottom) as pentachlorobenzene ( $\mathrm{MW}=250.3240)$, whereas the original spectrum (top) was regarded as bibenzyl $(\mathrm{MW}=182.2660)$. This suggested that the mass spectra of pentachlorobenzene had been buried among the compounds in the $\mathrm{EI}$ analysis, even though it was measured by $\mathrm{GC} \times \mathrm{GC}$. Even in this case, the mass spectra of molecular-related ions could be selectively obtained by NCI. Organohalogens can therefore be detected selectively and robustly by using NCI, but EI is important for identification by library searches. When enough separation cannot be achieved, even by using $\mathrm{GC} \times \mathrm{GC}$, data processing after measurement helps to strip out the compound that has been specified as the target from the others. Table 2 shows the numbers of halogenated compounds estimated in the soil sample assessed by using EI (method 1 in the table) or NCI (method 3) and additionally extracted from those data by CBEx using only an MDF (methods 2 and 4) as an example. (Supporting data, including the results of a NIST library search, are listed in Appendixes A to D as supplementary information (SI).) Comparison of the numbers of organohalogens estimated by using methods 1 and 3 confirmed that NCI had greater organohalogen detection power than EI. The number of organohalogens estimated from the data extracted with CBEx (652 compounds were estimated as organohalogens by an NIST library search) was about twice that estimated from the original data (301 organohalogens estimated). This suggests that CBEx stripped out the mass spectra of the organohalogens from the co-eluted components, which were not separated-even by $\mathrm{GC} \times \mathrm{GC}$. Table 3 lists the compounds estimated from a NIST library search of the data obtained by EI measurement and then processed or not processed with CBEx. A lot of organochlorines, including PCBs PCDDs, PCDFs, and chlorinated PAHs, were found from the data processed with CBEx; however, only a few organochlorines were estimated from the corresponding peaks in the unprocessed data. In contrast, we observed only a small difference in the number of organohalogens between the CBEx-extracted data and the original NCI data, suggesting that NCI is high selective.

Measurement of molecular ions is essential for identifying unknown compounds not registered in mass libraries. EI and NCI may not be enough; soft ionizations such as field ionization may be useful, despite insufficient ionization.

In conclusion, by using $\mathrm{GC} \times \mathrm{GC}$ combined with highly selective detection followed by sophisticated data analysis, we selectively and simultaneously detected and identified numerous organohalogen compounds, including hazardous chemicals such as PCBs and other POPs, without the need 
Fig. 3 Two-dimensional total ion chromatograms (2D-TICs) of a soil sample, as measured by using electron ionization $(E I)$, negative chemical ionization $(N C I)$, and data measured with EI and processed for selective extraction of organohalogens by using our original software (CBEx). Top, 2D-TIC from EI; middle, 2D-TIC from NCI; bottom, 2D-TIC from processed EI data
EI

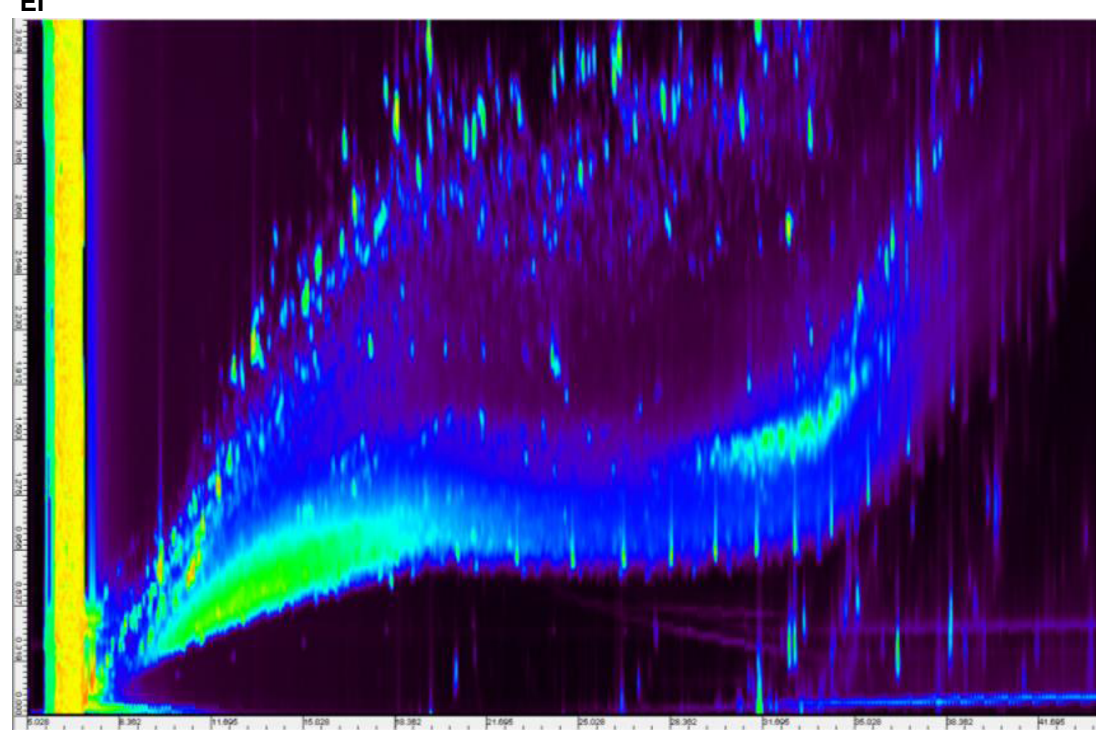

$\mathrm{NCl}$

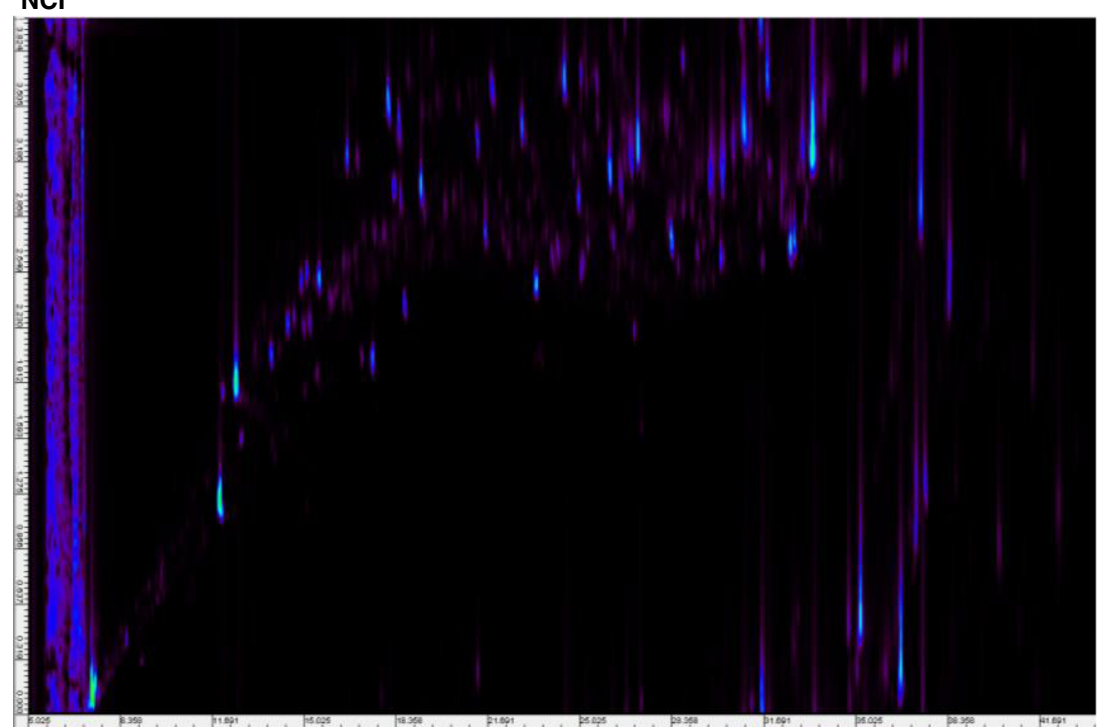

EI \& data processed with CBEx




Fig. 4 Mass spectra at the same location on 2D chromatograms of a soil sample, as measured by using electron ionization $(E I)$, negative chemical ionization $(N C I)$, and data measured with EI and processed for selective extraction of organohalogens by using original software $(C B E x)$. Top, mass spectrum from EI; middle, mass spectrum from NCI; bottom, mass spectrum from processed EI data
El

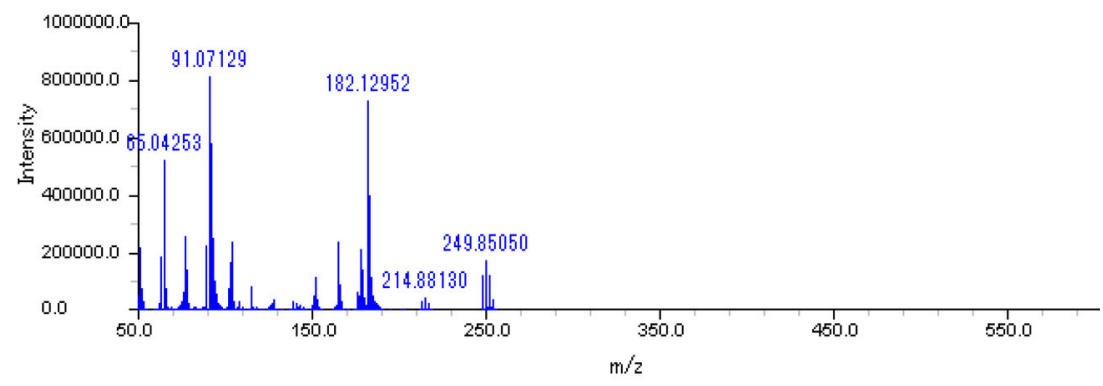

NCI

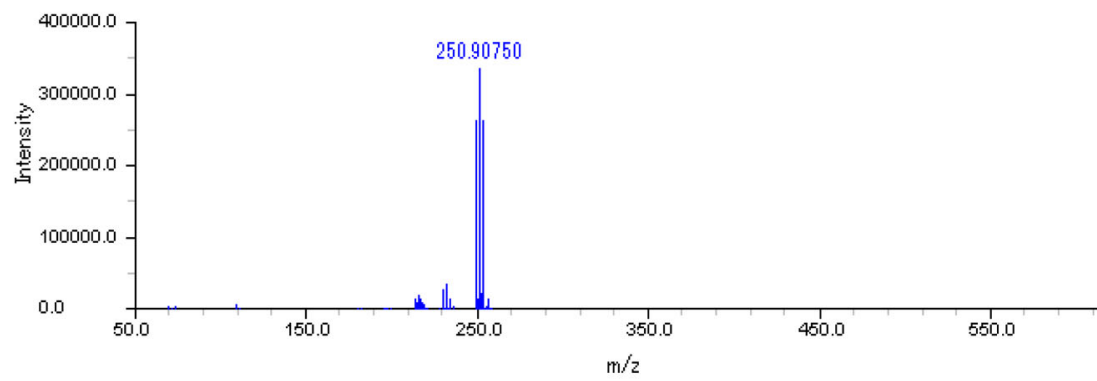

EI \& data processed with CBEx



to purify environmental sample extracts. Software determination using $\mathrm{GC} \times \mathrm{GC}-\mathrm{HRT}$ ofMS data, analysis via NCI with HRTofMS, and NLS with GC $\times$ GC-MS/MS were shown to be effective methods. In addition, deconvolution of the peaks and mass spectra effectively improved data extraction performance, because many compounds were co-eluted even when $\mathrm{GC} \times \mathrm{GC}$ was used, depending on the sample matrix. Further development of the hardware to improve its accuracy and precision, together with enhancement of the software to improve the matching of retention times in 2D chromatograms to those in $\mathrm{GC} \times \mathrm{GC}-\mathrm{HRT}$ ofMS spectra, will make it possible to simultaneously detect and quantify even more compounds.

Table 2 Numbers of compounds including the elements F, Cl, or $\mathrm{Br}$ in soil samples, as measured by using GC $\times$ GC-HRTofMS

\begin{tabular}{|c|c|c|c|c|}
\hline Method & Number of organofluorine & Number of organochlorine & Number of organobromine & Total \\
\hline 1. $\mathrm{EI}^{\mathrm{a}}$ & 103 & 137 & 61 & 301 \\
\hline 2. $\mathrm{EI}>\mathrm{CBEx}^{\mathrm{c}}$ & 119 & 420 & 113 & 652 \\
\hline 3. $\mathrm{NCl}^{\mathrm{b}}$ & 71 & 302 & 100 & 473 \\
\hline 4. $\mathrm{NCl}>\mathrm{CBEx}$ & 62 & 310 & 164 & 536 \\
\hline
\end{tabular}

Compounds were estimated by a search of the NIST mass spectra library 2011 (NIST11)

${ }^{a}$ Sample was measured by using positive electron ionization

${ }^{\mathrm{b}}$ Sample was measured by using negative chemical ionization

${ }^{\mathrm{c}}$ Data were extracted by using only mass defect filtering (as part of our CBEx original software) after measurement by each type of ionization method 







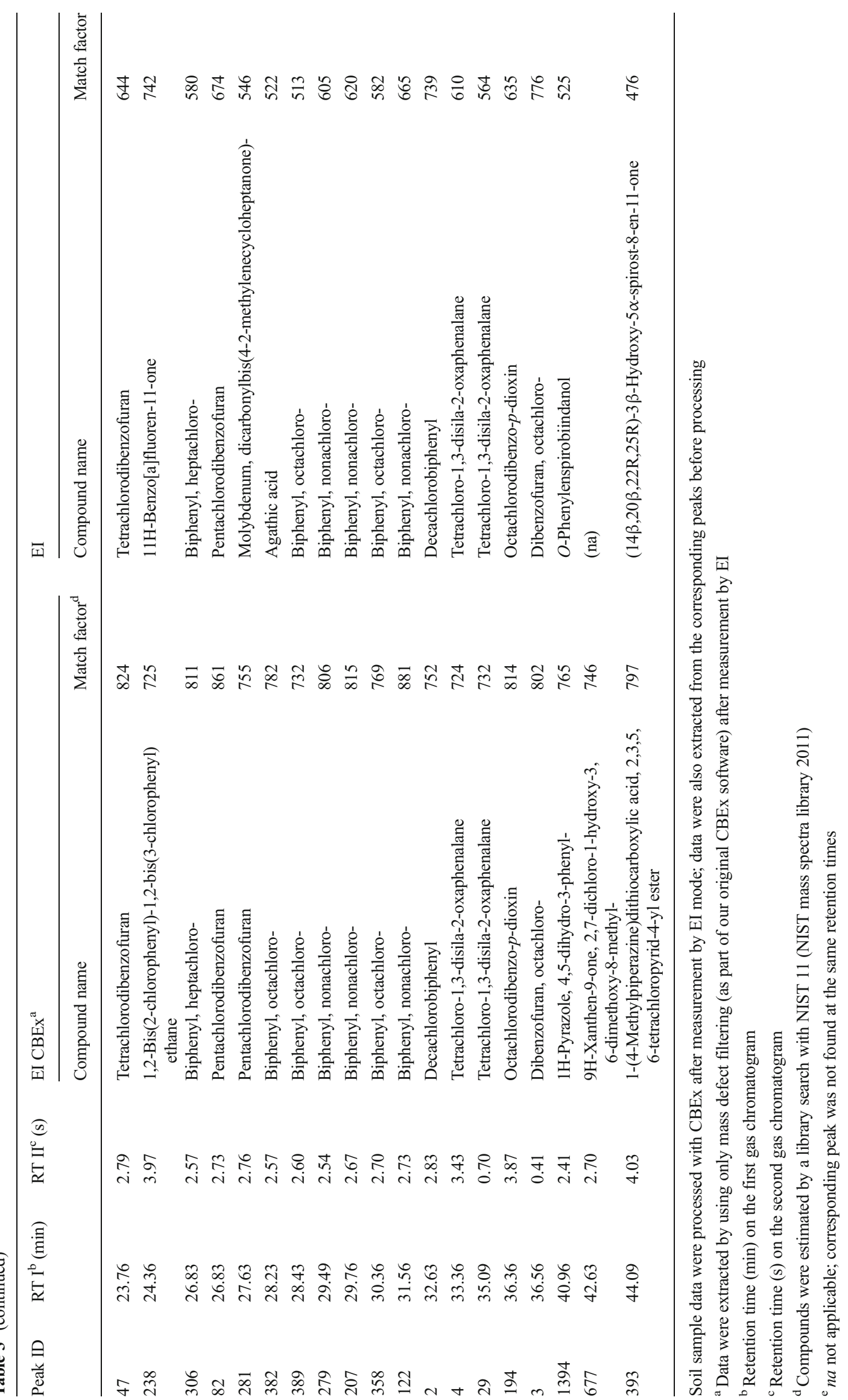


Acknowledgments We are grateful to Dr. Nobuo Ochiai and Dr. Hirooki Kanda of Gerstel K.K. for their technical support. We appreciate Dr. Takeshi Ohura of Meijo University for providing the halogenated PAH standards and valuable environmental samples. We thank Prof. Takeshi Nakano of Osaka University and Dr. Chisato Matsumura of the Hyogo Environmental Advancement Association for donating the urine samples. We also thank Ms. Yumiko Onizuka for the help in the preparation and measurement of samples. This work was partially supported by JSPS KAKENHI Grant Number 26241026.

Open Access This article is distributed under the terms of the Creative Commons Attribution 4.0 International License (http:// creativecommons.org/licenses/by/4.0/), which permits unrestricted use, distribution, and reproduction in any medium, provided you give appropriate credit to the original author(s) and the source, provide a link to the Creative Commons license, and indicate if changes were made.

\section{References}

Adahchour M, Beens J, Vreuls RJJ, Batenburg AM, Rosing EAE, Brinkman UAT (2002) Application of solid-phase micro-extraction and comprehensive two-dimensional gas chromatography (GCxGC) for flavour analysis. Chromatographia 55:361-368

Bicchi C, Amato AD, Rubiolo P (1999) Cyclodextrin derivatives as chiral selectors for direct gas chromatographic separation of enantiomers in the essential oil, aroma and flavour fields. J Chromatogr A 843:99-121

Blomberg J, Schoenmakers PJ, Beens J, Tijssen R (1997) Comprehensive two-dimensional gas chromatography $(\mathrm{GC} \times \mathrm{GC})$ and its applicability to the characterization of complex (petrochemical) mixtures. J High Resolut Chromatogr 20:539-544

Cajka T, Hajslova J, Kazda R, Poustka J (2005) Challenges of gas chromatography-high-resolution time-of-flight mass spectrometry for simultaneous analysis of polybrominated diphenyl ethers and other halogenated persistent organic pollutants in environmental samples. J Sep Sci 28:601-611

Carrizo D, Grimalt JO (2006) Rapid and simplified method for the analysis of polychloronaphthalene congener distributions in environmental and human samples by gas chromatography coupled to negative ion chemical ionization mass spectrometry. J Chromatogr A 1118:271-277

Danielsson C, Wiberg K, Korytar P, Bergek S, Brinkman UAT, Haglund $P(2005)$ Trace analysis of polychlorinated dibenzo-p-dioxins, dibenzofurans and WHO polychlorinated biphenyls in food using comprehensive two-dimensional gas chromatography with electron-capture detection. J Chromatogr A 1086:61-70

de Vos J, Dixon R, Vermeulen G, Gorst-Allman P, Cochran J, Rohwer E, Focant J-F (2011) Comprehensive two-dimensional gas chromatography time of flight mass spectrometry (GC $\times \mathrm{GC}-\mathrm{TOFMS})$ for environmental forensic investigations in developing countries. Chemosphere 82:1230-1239

Focant JF, Sjodin A, Patterson DG Jr (2003) Qualitative evaluation of thermal desorption-programmable temperature vaporizationcomprehensive two-dimensional gas chromatography-time-offlight mass spectrometry for the analysis of selected halogenated contaminants. J Chromatogr A 1019:143-156

Focant JF, Sjodin A, Patterson DG (2004) Improved separation of the 209 polychlorinated biphenyl congeners using comprehensive twodimensional gas chromatography-time-of-flight mass spectrometry. J Chromatogr A 1040:227-238

Fushimi A, Hashimoto S, Ieda T, Ochiai N, Takazawa Y, Fujitani Y, Tanabe K (2012) Thermal desorption-comprehensive two- dimensional gas chromatography coupled with tandem mass spectrometry for determination of trace polycyclic aromatic hydrocarbons and their derivatives. J Chromatogr A 1252:164-170

Hashimoto S, Takazawa Y, Fushimi A, Tanabe K, Shibata Y, Ieda T, Ochiai N, Kanda H, Ohura T, Tao Q, Reichenbach SE (2011) Global and selective detection of organohalogens in environmental samples by comprehensive two-dimensional gas chromatographytandem mass spectrometry and high-resolution time-of-flight mass spectrometry. J Chromatogr A 1218:3799-3810

Hashimoto S, Zushi Y, Fushimi A, Takazawa Y, Tanabe K, Shibata Y (2013) Selective extraction of halogenated compounds from data measured by comprehensive multidimensional gas chromatography/high resolution time-of-flight mass spectrometry for non-target analysis of environmental and biological samples. J Chromatogr A 1282:183-189

Hilton DC (2007) Current trends in mass spectrometry. http:// www.leco.com

Hilton DC, Jones RS, Sjödin A (2010) A method for rapid, non-targeted screening for environmental contaminants in household dust. J Chromatogr A 1217:6851-6856

Hites RA (2008) Electron impact and electron capture negative ionization mass spectra of polybrominated diphenyl ethers and methoxylated polybrominated diphenyl ethers. Environ Sci Technol 42: 2243-2252

Hyotylainen T, Kallio M, Hartonen K, Jussila M, Palonen S, Riekkola ML (2002) Modulator design for comprehensive two-dimensional gas chromatography: quantitative analysis of polyaromatic hydrocarbons and polychlorinated biphenyls. Anal Chem 74:4441-4446

Kallio K, Hyotylainen T (2007) Quantitative aspects in comprehensive two-dimensional gas chromatography. J Chromatogr A 1148: $228-235$

Korytar P, Leonards PEG, de Boer J, Brinkman UAT (2002) Highresolution separation of polychlorinated biphenyls by comprehensive two-dimensional gas chromatography. J Chromatogr A 958: 203-218

Korytar P, Danielsson C, Leonards PEG, Haglund P, de Boer J, Brinkman UAT (2004) Separation of seventeen 2,3,7,8-substituted polychlorinated dibenzo-p-dioxins and dibenzofurans and 12 dioxin-like polychlorinated biphenyls by comprehensive twodimensional gas chromatography with electron-capture detection. J Chromatogr A 1038:189-199

Korytar P, Covaci A, Leonards PEG, de Boer J, Brinkman UAT (2005) Comprehensive two-dimensional gas chromatography of polybrominated diphenyl ethers. J Chromatogr A 1100:200-207

Kristenson EM, Neidig HC, Vreulls RJJ, Brinkman UAT (2005) Fast miniaturized sample purification for the screening and comprehensive two dimensional gas chromatographic determination of polychlorinated biphenyls in sludge. J Sep Sci 28:1121-1128

Mao D, Lookman R, Van De Weghe H, Van Look D, Vanermen G, De Brucker N, Diels L (2009) Detailed analysis of petroleum hydrocarbon attenuation in biopiles by high-performance liquid chromatography followed by comprehensive two-dimensional gas chromatography. J Chromatogr A 1216:1524-1527

Ochiai N, Ieda T, Sasamoto K, Fushimi A, Hasegawa S, Tanabe K, Kobayashi S (2007) Comprehensive two-dimensional gas chromatography coupled to high-resolution time-of-flight mass spectrometry and simultaneous nitrogen phosphorous and mass spectrometric detection for characterization of nanoparticles in roadside atmosphere. J Chromatogr A 1150: $13-20$

Pena-Abaurrea M, Jobst KJ, Ruffolo R, Shen L, McCrindle R, Helm PA, Reiner EJ (2014) Identification of potential novel bioaccumulative and persistent chemicals in sediments from Ontario (Canada) using scripting approaches with $\mathrm{GC} \times \mathrm{GC}-\mathrm{TOF}$ MS analysis. Environ Sci Technol 48:9591-9599 
Shunji H, Yoshikatsu T, Akihiro F, Hiroyasu I, Kiyoshi T, Yasuyuki S, Masaaki U, Akihiko F, Kazuo T, Hideyuki O, Katsunori A (2008) Quantification of polychlorinated dibenzo-p-dioxins and dibenzofurans by direct injection of sample extract into the comprehensive multidimensional gas chromatograph/high-resolution time-of-flight mass spectrometer. J Chromatogr A 1178:187-198
Tranchida PQ, Shellie RA, Purcaro G, Conte LS, Dugo P, Dugo G, Mondello L (2010) Analysis of fresh and aged tea tree essential oils by using GCxGC-qMS. J Chromatogr Sci 48:262-266

von Muhlen C, Zini CA, Caramao EB, Marriott PJ (2006) Applications of comprehensive two-dimensional gas chromatography to the characterization of petrochemical and related samples. J Chromatogr A 1105:39-50 